\title{
Deposition of Colloidal Hematite onto Mercury from Water-Ethanol
}

\section{Mixtures}

\author{
Estela María Andrade ${ }^{a}$, Fernando Víctor Molina ${ }^{a}{ }^{*}$, and Dionisio Posadas ${ }^{b}$ \\ ${ }^{a}$ INQUIMAE, Departamento de Química Inorgánica, Analitica y Química Físi- \\ ca, Facultad de Ciencias Exactas y Naturales, UBA, Ciudad Universitaria, Pa- \\ bellón II, 1428, Buenos Aires Argentina \\ ${ }^{b}$ Departamento de Química, Facultad de Ciencias Exactas, Instituto de \\ Investigaciones Fisicoquímicas Teóricas y Aplicadas (INIFTA), UNLP, Suc. 4, \\ CC 16, 1900 La Plata, Argentina
}

Received: July 25, 1996

\begin{abstract}
A aderença de partículas de hematita $\left(\mathrm{a} \mathrm{Fe}_{2} \mathrm{O}_{3}\right)$ sobre eletrodos de mercúrio foi estudada em misturas de água-etanol através de contagem sobre imagens de um microscópio ótico. Quando o conteúdo de etanol é pequeno, o número de partículas aderidas decresce com o aumento da concentração de etanol. Para uma fração molar de etanol de 0,2 , o número de partículas passa por um mínimo, aumentando para maiores concentrações de etanol. Modificando o potencial eletródico, observa-se que as curvas número de partículas vs. Fração molar de etanol pode ser explicada com base na dependência com a composição do solvente das energias de interação partícula/solução e metal/solução.

The adherence of hematite $\left(\alpha \mathrm{Fe}_{2} \mathrm{O}_{3}\right)$ particles onto mercury electrodes in water-ethanol mixtures has been studied by counting using optical microscope images. The number of attached particles, when the ethanol content is small, decreases as the ethanol concentration increases. At a mole fraction of ethanol near to 0.2 , the number of particles goes through a minimum and then it increases with ethanol concentration. When the electrode potential is modified, curves of the number of particles $v s$. ethanol mole fraction with the same shape are found, but which cross each other.

The dependence on the ethanol concentration can be explained based on the dependence of particle/solution and metal/solution interaction energies with the solvent composition.
\end{abstract}

Keywords: hematite adhesion, metal surface, water-ethanol mixtures

\section{Introduction}

The attachment of colloidal particles onto metallic surfaces is a field relevant to many applied problems, such as corrosion protection, biofouling and semiconductor manufacturing, to mention only a few. However, it has not received much attention in fundamental studies. There are some published papers on adherence of particles to surfaces (usually non conducting) ${ }^{1-6}$ and to different particles ${ }^{7-12}$, where the surface electric potential cannot be easily modified. In our group we have studied the attachment of hematite parti- cles onto mercury and silver surfaces under different conditions ${ }^{13-16}$. Theoretical work has been mainly devoted to extension of the DLVO theory of colloid stability ${ }^{17}$ to heterocogulation (coagulation of dissimilar particles) ${ }^{18-20}$ or to the kinetics of deposition ${ }^{21-23}$.

Mixed solvent media has been used to study the ionic equilibrium at the hematite/solution interface ${ }^{24}$. In this work the influence of the solvent media is studied, by measuring the number of hematite particles attached onto mercury surfaces from suspensions in water-ethanol mixtures, using $\mathrm{NaClO}_{4}$ as the supporting electrolyte. The number of 
particles was measured by counting using video images, as a function of ethanol concentration at different applied potentials.

\section{Experimental}

\section{Preparation of hematite suspensions}

Hematite was synthesized as previously described ${ }^{13-15}$. The particle surface charges in water/ethanol media were determined by potentiometric titration ${ }^{24-25}$. A fixed amount of $\mathrm{HClO}_{4}$ was added to a suspension of $1.5 \mathrm{~g} \mathrm{dm}^{-3}$ hematite, and titrated with $\mathrm{NaOH}$. The resulting curve was compared with that of the blank electrolyte in order to obtain the isoelectric point and the charge - $\mathrm{pH}$ curve.

Oxide particles $\left(80 \mathrm{mg} \mathrm{dm}^{-3}\right)$ were suspended in $0.01 \mathrm{M}$ $\mathrm{NaClO}_{4}$ solutions in water/ ethanol mixtures for the deposition experiments. All reagents used were analytical grade. Water was obtained from a Milli-Q system and subsequently distilled with a sub-boiling point apparatus.

\section{Cell and apparatus}

A cell with three compartments was employed for the deposition experiments on mercury film electrodes which allowed the separate placement of a reference, an auxiliary, and the working electrode. A saturated calomel electrode (SCE) was used throughout as reference. Potential values in this work are refered to the SCE. A PAR Model 273 Potentiostat was used for the experiments.

\section{Hematite on mercury}

Mercury films were supported on silver discs of $0.5 \mathrm{~mm}$ diameter as it has been described before ${ }^{13}$. The colloid deposits were performed in water/ ethanol mixtures as follows:

i. The electrode potential was held for $30 \mathrm{~min}$ at -1.0 and $-0.3 \mathrm{~V}$; it has been found ${ }^{14}$ that these potentials correspond to the cathodic maximum and to a minimum of hematite deposition from water suspensions at $\mathrm{pH}=5$. Furthermore, as the zero charge potential of mercury in aqueous media is around $-0.5 \mathrm{~V}^{33}$, the potential values chosen should correspond to negatively and positively charged metal surfaces, respectively. All the experiments were done at $\mathrm{pH}=5$, as referenced to aqueous solution. In water-ethanol mixtures, the correction for the Born free energy of transfer between solvents was applied, as detailed by Heisleitner et al. ${ }^{24}$. This assured that the particles were in comparable charge states in the different mixtures.

ii. The electrode was placed "face up" at the bottom of the cell. When the deposition time was over, it was removed from the cell, rinsed carefully and dried. It was then observed under an optical microscope, Leitz DM RX, equipped with a video camera. Images were captured and processed using the Jandel Scientific MOCHA image analysis software.

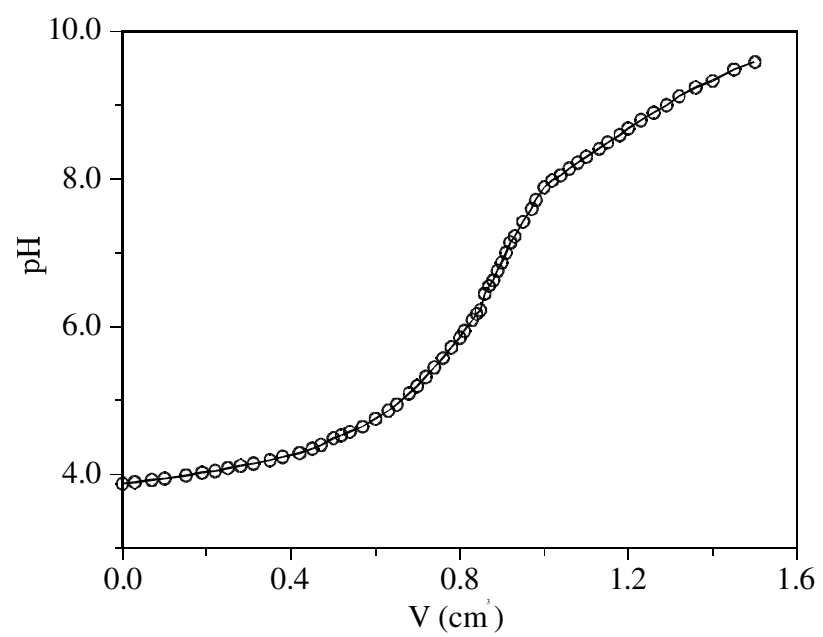

Figure 1. Titration curve of hematite in $0.01 \mathrm{M} \mathrm{NaClO}_{4}$, water/ethanol $\left(x_{\mathrm{Et}}=0.28\right) .0 .1453 \mathrm{~g} \mathrm{Fe}_{2} \mathrm{O}_{3}+50 \mu \mathrm{L} 0.08 \mathrm{M} \mathrm{HClO}_{4}$, titrated with $0.02 \mathrm{M} \mathrm{NaOH}$. $\mathrm{V}=100 \mathrm{~cm}^{3}$.

\section{Results}

Figure 1 shows a typical titration curve of hematite in water-ethanol medium. It is in general agreement with those obtained by Hesleitner $e t$ al. $^{24}$. The isoelectric point, i.e.p., was determined from the $\sigma v s$. $\mathrm{pH}$ plot, and found to be 7.4, the same as in the absence of ethanol ${ }^{13}$. The relative independence of the i.e.p. with ethanol concentration was also found by Hesleitner $e t$ al. $^{24}$.

In Fig. 2 typical video images obtained in the experiments are shown; in each experiment, several images were processed and their results averaged. Figure 3 presents the results obtained for the number of particles, $N_{\mathrm{d}}$, as a function of ethanol mole fraction, $x_{\mathrm{Et}}$ at the two potentials studied. $N_{\mathrm{d}}$ spans a wide range and therefore is plotted ogarithmically. It is observed that, as the ethanol content increases, a strong decrease in $N_{\mathrm{d}}$ occurs initially followed by a slower increase after reaching a minimum. At the two potentials the behavior is similar, but in the region of the minimum $N_{\mathrm{d}}$ an inversion is observed: the $N_{\mathrm{d}}$ at $-0.3 \mathrm{~V}$ is higher whereas in the extremes the opposite holds. It should be noted that at the two potentials studied the metal is expected to have charges of different sign, but no significant difference in the number of particles is found, indicating that the electrostatic interactions should not play a significant role in the observed behavior.

\section{Discussion}

The experimental results show that the attachment of hematite particles onto mercury surfaces has a relatively complex behavior. It shows an increase in the number of attached particles above an ethanol mole fraction of about 0.2 . This fact can be qualitatively explained on the basis of the changes of metal/solution and particle/solution interactions with $x_{\mathrm{Et}}$. To that end we will assume, in a general way, 
(a)
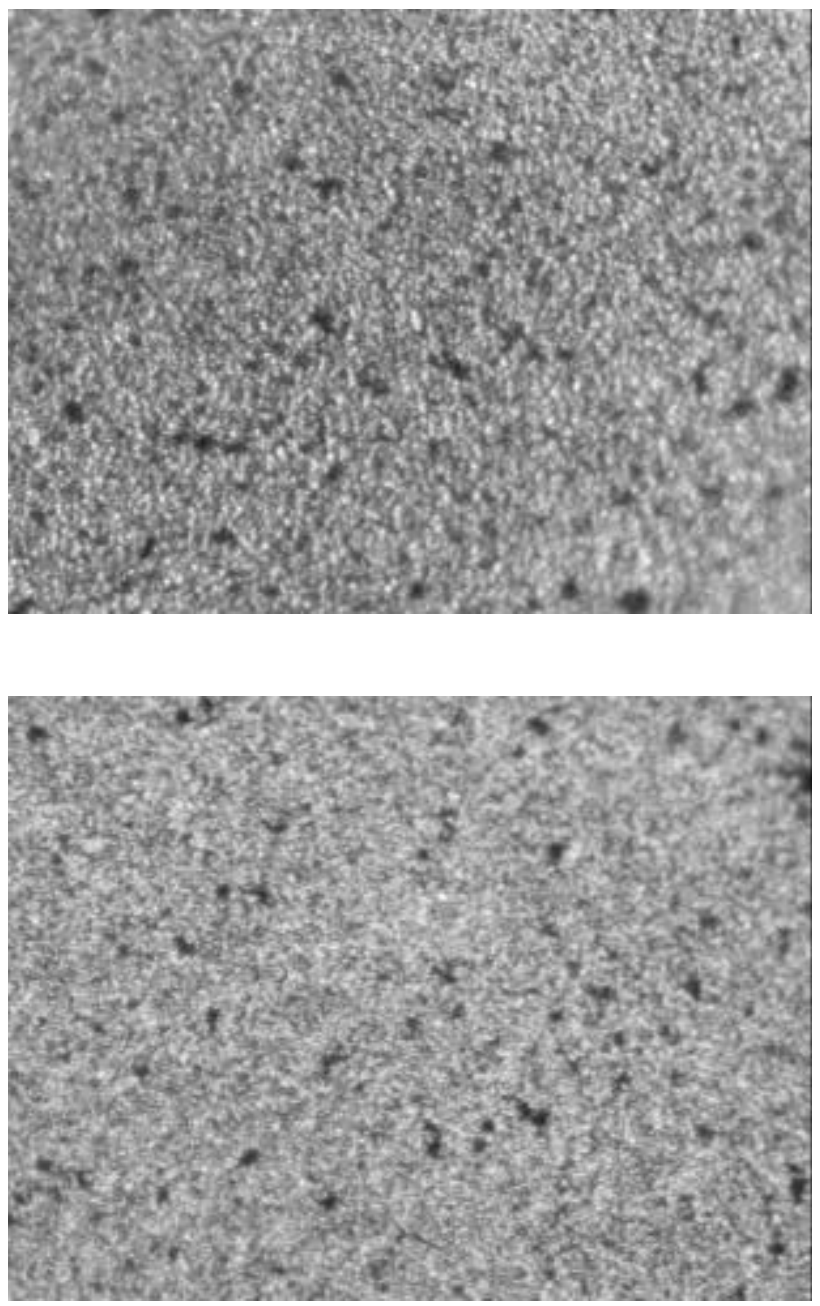

Figure 2. Images of mercury film electrodes with hematite particles attached. The particles are the dark points. The apparent texture is due to mercury film roughening when it is extracted from the cell. Image size: $260 \times 200 \mu \mathrm{m}^{2}$. (a) $x_{\mathrm{Et}}=0.09, \mathrm{E}=-0.3 \mathrm{~V}$; (b) $x_{\mathrm{Et}}=0.28, \mathrm{E}=-0.3$

that for particle/metal adhesion, the number of attached particles will increase as the (electrochemical) free energy of adhesion, $\Delta G_{\text {adh }}$, decreases. Then, we will consider its dependence with solvent composition.

The free energy change per unit area when two different surfaces (in this case metal, $\mathrm{M}$, and particle, $\mathrm{P}$ ) immersed in a third medium (solution, $\mathrm{S}$ ) attach to each other is given by $^{26}$ :

$$
\Delta G_{a d h}=\gamma_{M P}-\gamma_{P S}-\gamma_{M S}
$$

where $\gamma_{\mathrm{MP}}, \gamma_{\mathrm{PS}}$ and $\gamma_{\mathrm{MS}}$ are, respectively, the metal/particle, particle/solution and metal/solution surface energies. Each of these is, in turn, the sum of several contributions, namely Van der Waals (VW) forces (including dispersion and polarization), diffuse layer electrostatic interaction (el), chemical (chem), and image forces (im) ${ }^{26,27}$, so that

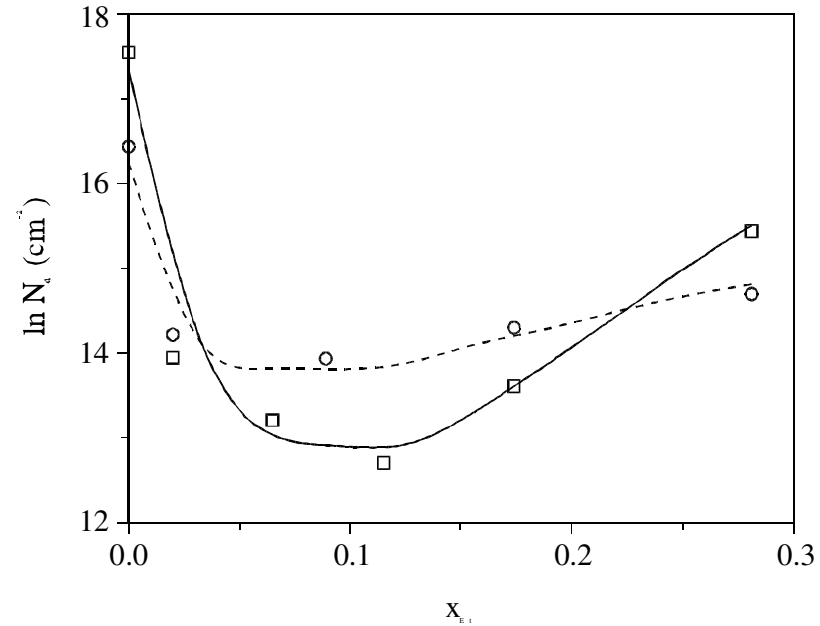

Figure 3. Logarithm of the number of particles as a function of $x_{\mathrm{Et}}$. $\square$ ) $-1.0 \mathrm{~V}$ vs. SCE; (o) $-0.3 \mathrm{~V}$ vs. SCE. $80 \mathrm{mg} \mathrm{dm}^{-3}$ hematite, $0.01 \mathrm{M}$

$$
\gamma_{i}=\gamma_{i}^{\mathrm{vw}}+\gamma_{i}^{\mathrm{el}}+\gamma_{i}^{\mathrm{chem}}+\gamma_{i}^{\mathrm{im}}
$$

where $i=$ MP, PS or MS. Then, $\Delta G_{\text {adh }}$ should, in general, be affected by all these contributions. The VW and electrostatic interactions are well known because they are considered in the colloid homo and heterocoagulation theories ${ }^{17,18,20}$. When the solvent is changed, all the contributions to $\gamma_{\mathrm{PS}}$ and $\gamma_{\mathrm{MS}}$ are expected to be modified, whereas $\gamma_{\mathrm{MP}}$ (the interfacial tension of metal and particle in close contact) can be regarded as constant. Then, the dependence of $\Delta G_{\text {adh }}$ on the ethanol mole fraction can be expressed as

$$
\Delta G_{\text {adh }}\left(x_{\mathrm{Et}}\right)=\Delta G_{a d h}^{\prime}\left(x_{\mathrm{Et}}\right)+\text { constant }
$$

where $\Delta G^{\prime}{ }^{\prime}{ }_{\text {adh }}\left(x_{\mathrm{Et}}\right)$ is the solvent dependent part of $\Delta G_{\text {adh }}\left(x_{\mathrm{Et}}\right)$. We will now consider the contributions to $\Delta G^{\text {adh }}\left(x_{\mathrm{Et}}\right)$ to estimate its variation with $x_{\mathrm{Et}}$. The behavior of $\gamma_{\mathrm{MS}}$ is well known for mercury/aqueous solution interfaces. It has been studied for water-ethanol mixtures by Ockrent ${ }^{28}$ using $\mathrm{NH}_{4} \mathrm{NO}_{3}$, and it shows the usual inverted parabola shape, with the maximum being lowered and shifted anodically as the ethanol concentration increases.

On the other hand, $\gamma_{\mathrm{PS}}$ is less known. Following Israelachvili ${ }^{26}$, it can be considered as the free energy change when a unit area of particle-particle surface is taken apart and brought in contact with the solution (Fig. 4), thus forming a unit area of particle-solution interface. This process is the opposite of particle coagulation, so that it can be written

$$
-\gamma_{\mathrm{PS}}=\Delta G_{\text {coag }}=\Delta G^{\mathrm{el}}+\Delta G^{\mathrm{vw}}+\Delta G^{\mathrm{chem}}+\Delta G^{\mathrm{im}}
$$

$\Delta G^{\mathrm{el}}$ and $\Delta G^{\mathrm{VW}}$ are the double layer and Van der Waals contributions to the energy change when two identical, plane surfaces are brought to contact from infinity; these are the interaction energies between identical particles, which 


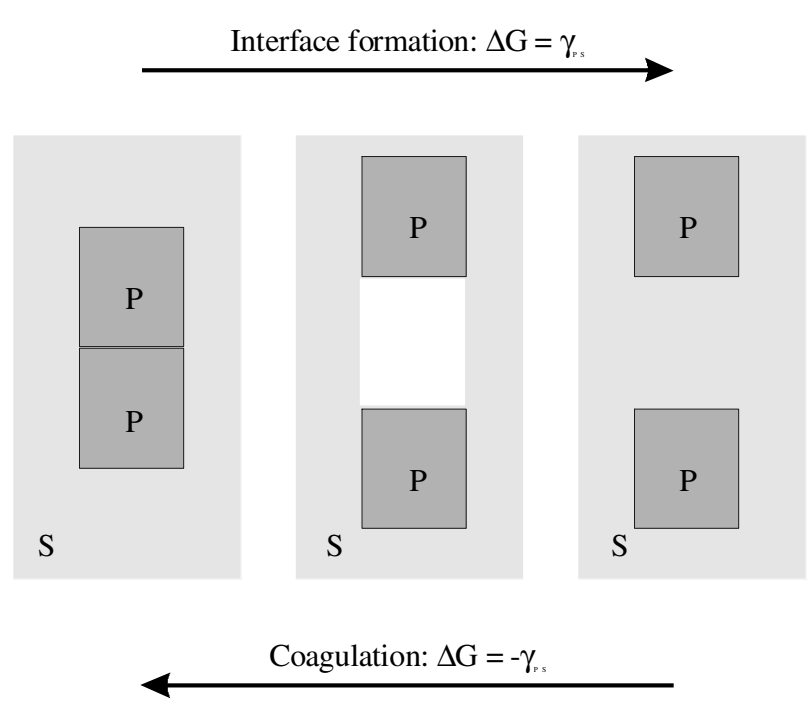

Figure 4. Schematic representation of the formation of a particle/solution interface, and its opposite process, from particle/solution to particle/particle interface; the latter is the coagulation process.

form the basis of DLVO and related theories of colloid particle interactions. Their dependence with the solvent composition can be obtained from the respective equations as follows.

The Van der Waals interactions

The Van der Waals interaction energy between two plane parallel surfaces at a distance $D$ apart is given by ${ }^{29}$ :

$$
W(D)=-\frac{A}{12 \pi D_{0}^{2}}
$$

so that $\Delta G^{\mathrm{VW}}$ is the energy difference between infinity and a minimum contact distance $D_{0}$, which can be taken as $0.165 \mathrm{~nm}^{29}$, that is

$$
\Delta G^{\mathrm{vw}}=-\frac{A}{12 \pi D_{0}^{2}}
$$

In Eqs. 5 and $6 A$, known as the Hamaker constant, is approximately given by

$$
A=\frac{3}{4} k T\left(\frac{\varepsilon_{P}-\varepsilon_{S}}{\varepsilon_{P}+\varepsilon_{S}}\right)^{2}+\frac{3 h}{4 \pi} \int_{v_{1}}^{\infty}\left[\frac{\varepsilon_{P}(i v)-\varepsilon_{S}(i v)}{\varepsilon_{P}(i v)+\varepsilon_{S}(i v)}\right]^{2} d v(7)
$$

where $\varepsilon_{\mathrm{P}}$ and $\varepsilon_{\mathrm{S}}$ are, respectively, the particle and solvent static dielectric constants, and $\varepsilon_{\mathrm{P}}(i v)$ and $\varepsilon_{\mathrm{S}}(i v)$ are approximately given by ${ }^{30}$ :

$$
\varepsilon(i v)=1+\frac{\left(n^{2}-1\right)}{1+\frac{v^{2}}{v_{e}^{2}}}
$$

where $n$ is the refractive index and $v_{\mathrm{e}}$ the main electronic absorption frequency. In Eq. 7 the integration is carried out in the optical frequency range, so the lower limit is usually taken as $^{29} v_{1} \approx 4 \times 10^{13} \mathrm{~s}^{-1}$. Eq. 7 includes the zero frequency interaction, with the Debye and Keesom contributions (first term) as well as the London dispersion energy (second term). $v_{\mathrm{e}}$ for water and ethanol can be taken ${ }^{29}$ as $3.010^{15} \mathrm{~s}^{-1}$ and for hematite, which absorbs in the visible range, $v_{\mathrm{e}} \approx 5.510^{14} \mathrm{~s}^{-1}$.

From Eqs. 7 and 8 it is clear that the Van der Waals interaction depends on the static dielectric constants and the refractive indices of both media, particle and solvent. For hematite, $\varepsilon_{\mathrm{P}}=12$ and $n_{\mathrm{P}}=3.05^{31}$. For water-ethanol mixtures, using the available data ${ }^{32}$, the dielectric constant can be approximately expressed, in the range $0 \leq x_{\mathrm{Et}} \leq 0.4$, as $\varepsilon p=78.5-59.5\left(x_{\mathrm{Et}}\right)^{1 / 2}$. On the other hand, as there is very little difference between the refractive indices of water (1.333) and ethanol (1.361), the $n_{\mathrm{S}}$ values are linearly interpolated.

Figure 5 shows the resulting $\Delta G^{\mathrm{VW}}$ as a function of ethanol mole fraction. A slight increase with $x_{\mathrm{Et}}$ is observed.

\section{The electrostatic interactions}

The subject of colloidal particle electrostatic interactions has been widely studied ${ }^{17-20,23}$. Hogg et al. ${ }^{19}$ gave the following approximate analytical expression, valid for low surface potentials, of the free energy change for two plane parallel double layers which are brought from infinity to a distance $D$ apart:

$$
\begin{gathered}
\Delta G^{\mathrm{el}}(D)=\psi_{0}^{2} \varepsilon_{P} \varepsilon_{0} \kappa[1-\operatorname{coth}(\kappa D)+ \\
+\operatorname{cosech}(\kappa D)]
\end{gathered}
$$

where $\Psi_{0}$ is the surface potential, $\varepsilon_{0}$ the vacuum permitivity and $\kappa$ is the inverse Debye-Hückel length, given for a 1-1 electrolyte by

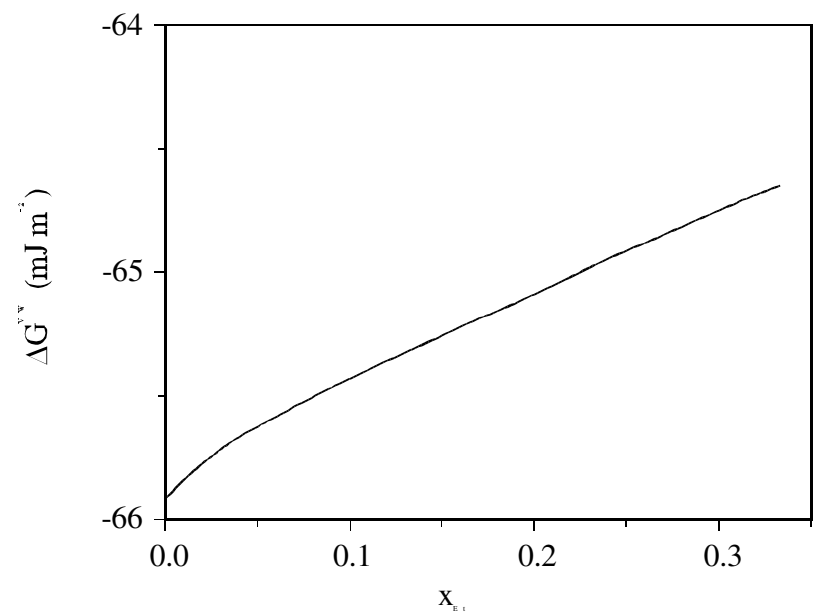

Figure 5. Van der Waals forces contribution to the free energy change of the coagulation process, as a function of ethanol mole fraction. 


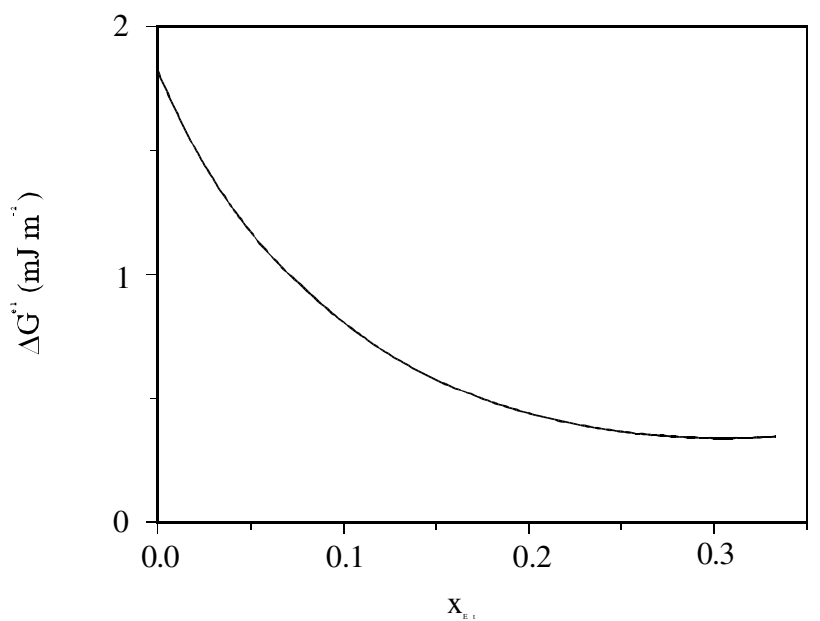

Figure 6. Electrostatic double layer interaction contribution to the free energy change of the coagulation process, as a function of ethanol mole fraction.

$$
\kappa=\left(\frac{2 c F^{2}}{\varepsilon_{P} \varepsilon_{0} R T}\right)^{1 / 2}
$$

c being the electrolyte concentration, and $F, R$ and $T$ have their usual meaning.

The surface potential $\Psi_{0}$ is a quantity relatively difficult to obtain. Instead, the so called $\zeta$ potential is customarily obtained from electrokinetic measurements. $\zeta$ is the potential value at the slipping plane in the electrolyte surrounding the particle. Heisleitner et al. ${ }^{24}$ have measured the $\zeta$ potential of hematite in water-ethanol mixtures, and gave an estimation of the distance from the outer Helmholtz plane to the slipping plane in the order of $1.2 \mathrm{~nm}$. From these data, approximate values for $\Psi_{0}$ can be obtained. With these values in turn, $\Delta G^{\mathrm{el}}$ at $D=D_{0}$, gives a dependence with $x_{\mathrm{Et}}$ as shown in Fig. 6.

The other contributions to $\gamma_{\mathrm{PS}}, \Delta G^{\mathrm{chem}}$ and $\Delta G^{\mathrm{im}}$ are not known, and initially they will be considered negligible, as is usually done ${ }^{17-20,27}$.

\section{The dependence of $\Delta G_{a d h}$ on solvent composition}

From Eqs. 1, 3, 4 and the above considerations, it can be written that

$$
\Delta G_{\text {adh }}^{\prime}=\Delta G^{e l}+\Delta G^{v w}-\gamma_{M S}
$$

Using data from Ref. 28 for $\gamma_{M S}$, the adhesion free energy dependence on $x_{\mathrm{Et}}$ is depicted in Fig. 7. It is observed that as the ethanol mole fraction is increased, $\Delta G_{\text {adh }}$ increases reaching a plateau at $\left.x_{\mathrm{Et}}\right) 0.25$. This is in qualitative agreement with the experimental findings. Mainly, the increase in the first part of the curve approximately matches the experimental decrease of $N_{\mathrm{d}}$ in this range. The decrease of $\Delta G_{\mathrm{adh}}$ at higher $x_{\mathrm{Et}}$ (and the corresponding increase in number of particles) can be attributed to a higher instability of the particles in a medium of low dielectric constant.

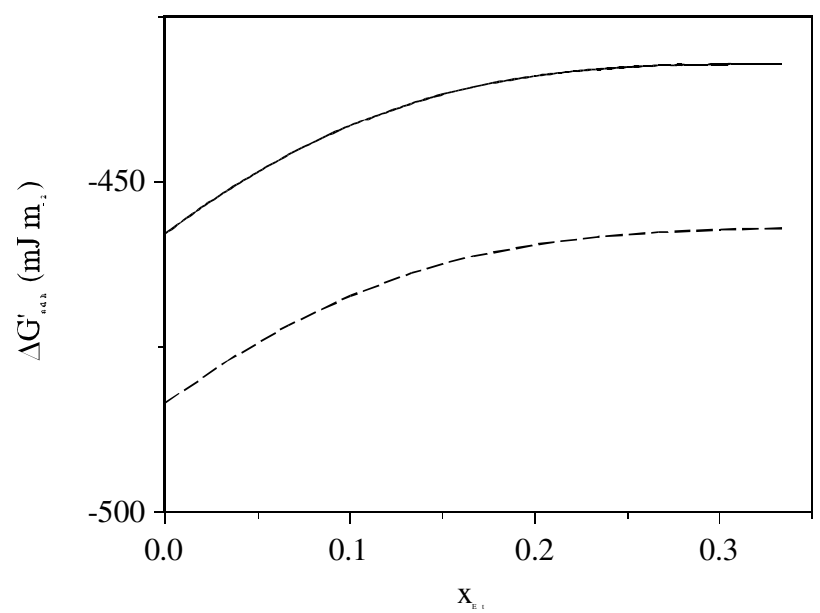

Figure 7. Solvent dependent part of the free energy of adhesion (calculated) as a function of ethanol mole fraction. Continuous line, -1.0 $\mathrm{V}$; dotted line, $-0.3 \mathrm{~V}$.

Although not generally considered, there should be a contribution of $\Delta G^{\text {chem }}$ to this effect. Because hematite is an oxide, the presence of hydrogen bonding between water and the particles should be expected. As the ethanol (which has less capability to form hydrogen bonds than water) content increases, the number of such bonds should diminish, and so diminishing the stability of the particles in suspension, thus favoring the deposition.

On the other hand, the above calculations do not explain the observed crossing of the $N_{\mathrm{d}} v s . x_{\mathrm{Et}}$ curves at different potentials. This is a difficult point to explain, because the electrode potential is assumed to affect $\gamma_{\mathrm{MP}}$ and $\gamma_{\mathrm{MS}}$ but not $\gamma_{\text {PS }}$. The dependence of $\gamma_{\text {MS }}$ with the ethanol concentration is monotonic and cannot lead to the behavior of Fig. 2. Although Ockrent ${ }^{28}$ used a different electrolyte than ours, it is unlikely that this difference could affect strongly the results. A possible explanation is that $\gamma_{\mathrm{MP}}$ could be solvent dependent, in addition to potential dependent. This might be due to a small amount of solvent being retained upon particle adhesion.

As it is mentioned above, the metal - particle electrostatic interactions do not appear to have significant influence in the observed behaviour, because the hematite particles have a positive charge at the $\mathrm{pH}$ studied here, whereas the metal has in one case negative charge and positive charge in the other case. The differences observed do not seem to be related to such interactions. In fact, the calculations show that $\gamma_{\mathrm{MS}}$ is the dominant term in $\Delta G^{6}$ adh, that is, the energy gained in diminishing the metal-solution interfacial area seems to overcome other contributions.

\section{Acknowledgments}

Grateful acknowledgement is made to the Consejo Nacional de Investigaciones Científicas y Técnicas (CONICET) de la República Argentina for support of this work. E.M.A. 
and F.V.M. are also indebted to the Grupo de Electroquímica and to INQUIMAE for partial support of this work.

\section{References}

1. Marshall, J.; Kitchener, J. J. Colloid Interf. Sci. 1966, $22,342$.

2. Hull, M.; Kitchener, J. Trans. Far. Soc. 1969, 65, 3093.

3. Usui, S.; Yamasaki, T. J. Colloid Interf. Sci. 1969, 29, 629.

4. Dabros, T.; van de Ven, T.G.M. Colloid Surf. A: Physic. Eng. Aspects 1993, 75, 95.

5. Sjollema, J.; Buscher, H.J. J. Colloid Interf. Sci. 1989, $132,382$.

6. Ryde, N.; Kihira, H.; Matijevic, E. J. Colloid Interf. Sci. 1992, 151, 421.

7. Urrutia, G.; Pasaggio, S.; Maroto, A.; Blesa, M.A. Nucl. Sci. Eng. 1983, 84, 120.

8. Kallay, N.; Barouch, E.; Matijevic, E. Adv. Colloid Interf. Sci. 1987, 27, 1.

9. Kuo, R.J.; Matijevic, E. J. Colloid Interf. Sci. 1980, 78, 407.

10. Caselli, M.; Lippolis, G.; Gierst, L. J. Electroanal. Chem. 1972, 38, 451.

11. Cohen, H.; A. Soffer Y.; Oren, J. Colloid Interf. Sci. 1987, 120, 272.

12. Alince, B. Colloids Surf. 1989, 34, 39.

13. Andrade, E.M.; Molina, F.V.; Posadas, D. J. Colloid Interf. Sci. 1994, 165, 450.

14. Andrade, E.M.; Molina, F.V., Gordillo, G.J.; Posadas, D. J. Colloid Interf. Sci. 1994, 165, 459.

15. Andrade, E.M.; Gordillo, G.J.; Molina, F.V.; Posadas, D. J. Colloid Interf. Sci. 1995, 173, 231.
16. Andrade, E.M.; Molina, F.V.; Posadas, D. J. Colloid Interf. Sci. 1995, 176, 450.

17. Verwey, E.; Overbeek, J.T. In Theory of the Stability of Lyophobic Colloids; Elsevier, Amsterdam, 1948.

18. Derjaguin, B. Disc. Faraday Soc. 1954, 18, 85.

19. Hogg, R.; Healy, T.; Fuerstenau, D. Trans. Far. Soc. 1966, 62, 1638.

20. Usui, S.In Progress in Surface and Membrane Science; Danielli, J. F. Ed.; 5, 223, 1972.

21. Adamczyk, Z.; Siwek, B.; Zembala, M. Colloid Surf. 1992, 62, 119.

22. Adamczyk, Z.; Siwek, B., Zembala, M.; Belouschek, P. Adv. Colloid Interf. Sci. 1994, 48, 151.

23. Adamczyk, Z.; Warszynski, P. Adv. Colloid Interf. Sci. 1996, 63, 41.

24. Hesleitner, P.; Kallay, N.; Matijevic, E. Langmuir 1991, 7, 178.

25. Regazzoni, A.E. Ph. D. Thesis, Buenos Aires, 1984.

26. Israelachvili, J.N. In Intermolecular and Surface Forces; Academic Press, London, 1985, ch. 14.

27. Bowling, R.A. In Particles and Surfaces; Mittal, K.L. Ed.; Plenum Press, New York, 1988.

28. Ockrent, C. J. Phys. Chem. 1931, 35, 3354.

29. Israelachvili, J.N. In Intermolecular and Surface Forces; Academic Press, London, 1985, ch. 11.

30. Mahanty, J.; Ninham, B.W. In Dispersion Forces; Academic Press, New York, 1976.

31. CRC Handbook of Chemistry and Physics; Lide, D.R. Ed.; CRC Press, Florida 1995.

32. International Critical Tables; Washburn. ,E. Ed.; McGraw-Hill, New York, 1929 Vol. IV.

33. Delahay, P. In Double Layer and Electrode Kinetics; Interscience, New York, 1965. 